\title{
ORgANISERAD BROTTSLIGHET I NORDEN
}

Av ChefsJuristen, DR. Lars Korsell och Professor, DR.POlit. PaUl Larsson

Organised crime in the Nordic context could best be characterized by two extremes. On one hand, there are the ad hoc-groups that form to carry out criminal enterprises such as smuggling operations. These ad hoc-groups are flexible and collaborators can come and go depending on the projects. The ad hoc-groups are quite discrete and profit is their primary goal. On the other hand, there are the brotherhoods of visible and often provocative gangs. Identity and brotherhood are often more important for these outlaw bikers, street gangs and similar gangs than the criminal enterprise itself. The ad hoc-groups are more common and thus more central to the criminal markets than the brotherhoods, even though the latter get a lot of media and political attention because of their characteristics. The nature of Nordic organised crime grows out of broader societal traits. The level of corruption is low, and people trust the political assemblies, the authorities and the judicial system as a whole. Longstanding democratic traditions, also on the local level, and relative economic equality help to explain why organised crime is not a threat even if there are problems*

\section{Ad hoc-grupper och broderskap}

Det finns över ett hundra definitioner på begreppet organiserad brottslighet (von Lampe 2009). För att skona läsaren från en sådan genomgång kan i stället två ytterligheter av organiserad brottslighet beskrivas. Mellan ytterligheterna förekommer givetvis en rad mellanformer. På den ena kanten finns grupperingar med inriktning på att genomföra kriminella projekt. De är ofta lösa, flexibla och mer eller mindre tillfälliga. De kan kallas för ad hoc-grupperingar (Larsson 2008). På den andra kanten finns ytterligheten med broderskapen (Larsson 2008). Hells Angels, Bandidos och Outlaws är tydliga exempel liksom Werewolf Legion, Wolfpack och Original Gangster (Korsell, Skinnari och Vesterhav 2009).

När organiserad brottslighet förs på tal tänker de flesta på broderskapen. De syns och hörs, uppfattas som hotfulla och bärs upp av identitet och sammanhållning. De får också mycket uppmärksamhet av medier, politiker och myndigheter. I den vanliga världen är de ändå ganska ovanliga. Den vanligaste formen av organiserad brottslighet är de mer nätverksabaserade ad hoc-grupperingarna. Det gäller i Norden och övriga Europa, sannolikt också i hela världen.

\footnotetext{
* Title in English: Organised Crime in the Nordic Countries. Original in Swedish.
} 
Låt oss titta närmare på dessa broderskap innan vi går över till ad hoc-grupperingarna.

\section{Broderskapen}

Kännetecknande för broderskapen är att det finns täta kopplingar mellan medlemmarna (Larsson 2008). "Broder" står för ett innehåll och medlemmar kan till och med känna större tillhörighet till grupperingen än sin egen familj. Identiteten är starkt knutet gruppen. Medlemskapet manifesteras utåt genom att gruppen har ett namn och att medlemmarna bär olika symboler, har särskilda tatueringar och uttrycker sig genom klädstilen.

Det förekommer ofta initieringsriter. Medlemskap kan föregås av en prövotid där personen testas. Sedan bekräftas medlemskapet och tillhörigheten till gruppen genom en ritual. Det påminner lite om frimurarlogerna och historiskt var den sicilianska maffian inspirerad av denna organisation (Paoli 2003). Ett väsentligt inslag med ritualerna är att medlemmen bryter banden med dem som finns "utanför" gruppen. På det sättet uppstår en stark känsla av att tillhöra ett större "vi" och därmed uppstår också ett avstånd till andra grupper, som ofta karaktäriseras som ett hot. Medlemmarna skyddar också varandra "som bröder". Centrala begrepp är heder och ära. Tillsammans leder dessa egenskaper hos broderskapen att avståndet är mycket kort att hamna i konflik med andra grupper. Svar på kränkningar och behovet av att stå upp för grupperingen gör att små konflikter snart blir stora. Följaktligen är det inte ovanligt att våldsamheter eskalerar. Tydliga exempel är "det nordiska mc-kriget" på nittiotalet, som skördade en rad dödsfall (Wierup och Larsson 2007). I Oslo pågår uppgörelser mellan A- och B-gängen. De har sitt ursprung i den pakistanska miljön. I Köpenhamn drabbar invandrargäng samman med "rockers". Dessa uppgörelser framställs ofta som någorlunda affärsmässigt motiverade konflikter om narkotikamarknader och pengar. I själva verket är inslaget av gamla personliga konflikter stort. Konflikter som sedan spårar ur.

För broderskapen kommer inte de kriminella ekonomiska aktiviteterna i främsta rummet utan identitet och tillhörighet. Det hindrar inte att personer inom sådana miljöer kan ägna sig åt olika former av kriminalitet som generar betydande belopp. Tillhörigheten till broderskapet innebär dessutom ett visst skydd. Den brottsliga verksamheten kan sedan utvecklas och övergå till mer traditionella former av organiserad brottslighet. I riktning mot ad hoc-grupperingar. Medlemmar i broderskap kan också samarbeta med ad hoc-grupperingar (Brå 2007:7).

De nyss nämnda A- och B- gängen började som ungdomsgäng och utvecklades till broderskap med en tidvis hög våldsnivå. Medlemmar i dessa grupper har också tjänat en hel del pengar på sin kriminalitet. Enligt en dom hade betydande belopp tvättats och investerats i Latinamerika. 
Ett annat exempel är mc-gängen, där genomsnittsåldern bland medlemmarna börjar närma sig de femtio. Dessa gäng består av personer med en blandning av både vit, grå och svart kriminell bakgrund (Brå 1999:6). Enligt norska uppgifter från KRIPOS är en så stor andel som två tredjedelar av medlemmarna inte kriminellt belastade. Samtidig vet man att enskilda personer i dessa miljöer är involverade i flera former av kriminalitet, bland annat torpedverksamhet och narkotikasmuggling (Brå 2005:11, Brå 2007:7, Brå 2007:4). Imagen och myten kring mc-gängen - 1 \% gängen - är välkända. Den kriminella identiteten är en inte oväsentlig del av outlaw imagen. Mc-gängen är utagerande och utmanande. Det i sin tur attraherar personer som vill tillhöra gängen, fascinerar medierna, retar upp politiker, triggar myndigheterna till insatser och skrämmer allmänheten (Brå 2010).

\section{Ad hoc-grupperingarna}

Även om mc-gäng och andra synliga broderskapsgrupperingar med dramatiska namn och symboler blivit något av den organiserade brottslighetens officiella ansikte utåt rör sig det mesta under ytan. Som nämndes inledningsvis har de mycket vanligare ad hoc-grupperingar fătt lite uppmärksamhet jämfört med de bullriga broderskapen. Ad hoc-grupperingarna arbetar för det mesta diskret och vill helst undgå uppmärksamhet eftersom det är "bad for business" (Brå 2005:11, Brå 2007:4, Brå 2007:7, Johansen 1996, Johansen 2005). De mest affärsmässigt inriktade personerna i ad hoc-grupperingarna är säkert tacksamma över det fokus samhället riktar mot broderskapen.

Logiken för att gå samman i ad hoc-grupperingar är ekonomisk (Korsell, Skinnari och Vesterhav 2009). För att uppnå volym och vinst har enstaka brott övergått till en kriminell verksamhet. Därför behövs kompanjoner och medarbetare - helt enkelt en gruppering - för att driva en verksamhet med långsiktighet och kontinuitet. Vissa arbeten kräver hantverksskicklighet, exempelvis för att konstruera lönnutrymmen i smugglingsbilar (Brå 2005:11). Andra arbeten är särskilt riskfyllda och därför rekryteras narkotikakurirer i stort behov av pengar (Brå 2005:7). Listan på medarbetare och hjälpredor kan göras mycket lång och organisationen bestäms efter de uppgifter som ska utföras.

Ofta drivs verksamheten småskaligt och går upp och ner i intensitet beroende på vad man håller på med. Vissa arbeten är också i hög grad tillfälliga eller kräver lite engagemang, som att förvara narkotika eller pengar (Brå 2007:4). Det är också vanligt att medarbetare går in och ur olika projekt. Den kriminella arbetsmarknaden är följaktligen mycket flexibel. Samtidigt medför denna ständigt förändrade organisationsstruktur att det blir svårare för myndigheterna att upptäcka och stoppa aktiviteterna. Om någon blir gripen eller av andra skäl faller bort kan verksamheten anpassas till de nya förhållandena. 
En småskalig verksamhet i ständig rörelse bör också bli mindre sårbar för förskingring och stöld. Kriminella lever särskilt laglöst utan myndigheters beskydd. Även om organiserad brottslighet från organisatoriska och ekonomiska utgångspunkter kan uppfattas som primitiv och dåligt utvecklad har den visat sig vara stryktålig. Ett tydligt bevis är att myndigheternas årtionden av krig mot narkotikan knappast varit framgångsrikt.

Småskaligheten innebär att det inte finns någon kriminell konspiration och intresset av att påverka lagstiftare, politiker och medier är obefintligt (Korsell 2008). Det finns varken vilja eller förmåga att angripa samhällets institutioner på den strategiska nivån. De kriminella grupperingarna nöjer sig med att tjäna pengar, undgå att åka fast och utöva otilllåten påverkan mot mer närliggande hot. Till exempel brottsoffer som ställer upp och vittnar eller poliser som går i vägen (utvecklas nedan). Sedan får samhället sköta sig bäst det kan. Det är också på marknaderna ad hoc-grupperingarna agerar.

Efterfrågan tillgodoses med "skattefria" varor och tjänster i form av insmugglad alkohol och tobak (von Lampe 2005). Särskilt spritsmuggling har en lång historia i Norden (Johansen 1993, Johansen 2004, Johansen 2005, Johansen 2009). Under första världskriget infördes restriktioner på alkohol och snart var entreprenörerna på plats för att fylla tomrummet med smuggling och hembränning. Smugglingen fortsatte när förbud och ransoneringar byttes ut mot höga skatter. Logistiken fanns på plats liksom kompetens och kontakter.

Ad hoc-grupperingarna är också involverade i mer omfattande former av svart arbete, särskilt inom byggsektorn och städbranschen (Brå 2007:27). På arbetskraftssidan är steget nära till illegala tjänster i form av människosmuggling och människohandel för arbetskraftsexploatering. Ekonomiska skillnader mellan länder och regioner i kombination med bristande framtidsmöjligheter skapar en marknad för att betala människosmugglare eller hamna i människohandel (Aas 2007). I rikare länder som de i Norden finns efterfrågan på billig arbetskraft. Det gäller städare, byggjobbare, jordbruksarbetare och andra arbeten med låga inträdeströsklar.

Den mest uppmärksammade formen av människosmuggling handlar dock om prostitution och koppleriverksamhet, klassiska områden för organiserad brottslighet (Lehti och Aromaa 2004, Viuhko och Jokinen 2009).

Illegala tjänster tar också sikte på hårdhänta former av indrivning. Tvister om svarta pengar och kriminella affärsöverenskommelser kan inte hanteras av kronofogden. Dessutom hindras inte illegala indrivning och inkassoverksamhet av hämmande regler. Från indrivning är steget inte långt till utpressning och beskyddarverksamhet. Verksamheten har då övergått från att utföra tjänster till att parasitera på andra, ofta småföretagare. Även om utpressning och beskyd- 
darverksamhet på ett internationellt plan utgör en traditionell inkomstkälla för organiserad brottslighet har det varit ett relativt ovanligt inslag i Norden (Korsell, Skinnari och Vesterhav 2009). På senare tid synes dock indrivning och beskydd öka även här.

Indrivning, utpressning och beskyddarverksamhet förefaller dock vara en nisch där snarare broderskapen än ad hoc-grupperingarna dominerar (Brå 2009:7). Förklaringen ligger i det våldskapital och dåliga rykte broderskapen kan exploatera. Västar med ryggmärken och hotfulla symboler kan få den mest betalningsovillige att komma på andra tankar. Möjligen kan framväxten av broderskapsgrupperingar vara en förklaring till att denna kriminalitet synes öka.

Illegala varor utgör en stor del av ad hoc-grupperingarnas verksamhet. Framför allt gäller det narkotika och dopningspreparat. Om spriten var den stora varan för organiserad brottslighet fram till andra världskriget har narkotikan dominerat efterkrigstiden, även på ett internationellt plan (Arlacchi 1986). Sedan dess har preparaten blivit fler och nått bredare grupper, trots "kriget mot narkotikan" (Wierup och de la Reguera 2010). Även om narkotika är en typisk importvara har på senare tid cannabisodling börjat bedrivas i industriell skala även i Norden (Larsson 2009, Larsson 2009b). Tidigare var det främst ett ämne för hemmaodlare och kunde knappast förknippas med organiserad brottslighet.

Andra illegala varor utgörs av vapen. Det är en missuppfattning att organiserad brottslighet kännetecknas av våld, men vapen innebär en försäkring samtidigt som det för många ingår i garderoben för en kriminell livsstil (Brå 2007:7). Mycket vapen är därför i omlopp. Det är heller inte någon brist på handeldvapen, kulsprutepistoler och automatkarbiner. De tidigare krigen i Jugoslavien lämnade efter sig mycket vapen där merparten ändå torde gå till oroshärdar runt om i världen och inte organiserad brottslighet.

Ett ofta förbisett område för organiserad brottslighet är handel med stöldgods (Brå 2006:6). Det är en stillsam aktivitet med uppenbara tentakler in i näringslivet, särskilt när det gäller organiserade stölder av metaller, lastbilslaster och lagervaror. Andra stöldobjekt är bilar och båtar för export.

Även rånare kan ibland räknas till ad hoc-grupperingarna, även om det då mer handlar om organiserade brott, ibland mycket organiserade, än organiserad brottslighet i betydelsen löpande kriminell verksamhet (Korsell, Skinnari och Vesterhav 2009).

För att skydda verksamheten är otillåten påverkan i form av hot, våld, skadegörelse, trakasserier och korruption förekommande (Korsell och Skinnari 2010). Brottsoffer och i någon mån vittnen utsätts för att inte samarbeta med myndigheterna (Brå 2008:8). Olika myndighetspersoner som poliser och tullare är också utsatta. Broderskapen är mer aggressiva än de ad hoc-grupperingarna. För broder- 
skapen och personer i den kriminella miljön kan otillåten påverkan mot myndighetspersoner vara ett sätt att meritera sig (Brå 2009:7). En förhållandevis vanlig form av otillåten påverkan är trakasserier, som inte behöver bestå av straffbara gärningar. När våld och hot förekommer sker det ofta i konfrontationer när känslorna är upphettade.

Även om ad hoc-grupperingarna på det beskrivna sättet svarar för en stor del av den kriminella ruljansen finns inte några vattentäta skott till personer inom broderskapen. Som tidigare nämnts samarbetar människor och går in och ut projekt, utför olika tjänster och medverkar på olika sätt. Samtidigt är gränsen från organiserad brottslighet och vardagsbrottslighet hårfin. Gråtjuvar och missbrukare kan vara leverantörer av stöldgods som går hela vägen till större hälare. Gatulangare och andra detaljister kan i sin tur via något distributionsled vara den yttersta länken i kedjan från knarkbaroner i Colombia, internationella smugglingsnätverk och inhemska ad hoc-grupperingar (Brå 2010).

\section{Etniska grupper och hotet utifrån}

Visserligen är de nordiska länderna tämligen homogena, med det förekommer ändå en del etniska grupperingar. Ett typiskt inslag för Finland är ryska och estniska kriminella grupperingar (Viuhko et al. 2009, Junninen 2006, Junninen och Aromaa 1999). I Sverige och Norge förekommer i sin tur grupperingar där ursprunget kan spåras till konflikterna i forna Jugoslavien. Till det kommer utvecklingen på Balkan med ett inslag av Kosovo-Albaner i Sverige och Norge. Tidigare nämndes de pakistanska gängen i Oslo med våldsamma uppgörelser dem emellan. I Norge förekommer också ett vietnamesiskt inslag med inriktning på småstölder, men där den totala volymen blir betydande. Den mest väldokumenterade gruppen är dock litauer.

Det ligger dock nära till hands att peka ut att "andra" svarar för den organiserade brottsligheten. I den av populärkultur och medier färgade mytbilden av organiserad brottslighet är det knappast grannen som misstänks. Brottsligheten kommer gärna "utifrån".

När järnridån föll befarade många att den östeuropeiska maffian skulle breda ut sig som en flodvåg över Europa (Levi 2002). Scenariot infriades aldrig och en viktig förklaring är det tydliga marknadsinriktade inslaget i organiserad brottslighet. För att löpande nå ut på en marknad förutsätts kunskap om de lokala förhållandena och uppbackning av åtskilliga personer och nyckelspelare som verkar och lever i lokalsamhället (Korsell, Skinnari och Vesterhav 2009). I annat fall är riskerna för stora att bli utsatt för stölder av andra kriminella eller bli gripen av myndigheterna.

Det nyss nämnda ryska och estniska inflytandet i Finland skiljer sig från den 
allmänna bilden, men kan förklaras av geografiska och handelsmässiga förhållanden. Dessutom är de finska och estniska språken besläktade med varandra.

Inom människohandel för sexuell exploatering och koppleri är det östeuropeiska inslaget stort och bakgrunden är att åtskilliga kvinnor rekryteras från Polen, Baltikum, Ryssland och Bulgarien (Brå 2008:24). Typiskt för människohandel är att samma gruppering svarar för hela kedjan, från rekrytering i ursprungslandet och försäljning av sexuella tjänster i mottagarlandet. Även om kvinnorna i den allmänna debatten ibland med retoriska ordalag likställs med "varor" är den vanliga situationen att de rekryteras och arbetar för en huvudman, inte att de säljs mellan traffickerare och deras grupperingar.

Det är därför skillnad mellan att rekrytera människor och att handla med varor. Exempelvis fungerar narkotikamarknaden på det sättet att varan ständigt byter ägare i distributionsledet, inte att en och samma gruppering hanterar alla eller åtskilliga led. Även om de lokala förbindelserna är grundläggande för organiserad brottslighet är följaktligen ett betydande inslag i brottsligheten import och handel med varor. Internationella kontakter och förtroendefulla relationer är därför viktiga för att inte bli lurad och kunna göra säkra affärer. För affärsverksamheten är det därför nästan nödvändigt att inbegripa personer med ett förflutet i exportlandet eller på annat sätt har goda förbindelser och uppbär förtroende. Det är en av flera förklaringar till det internationella inslaget i organiserad brottslighet.

Myndigheter hänvisar ofta till att personer från olika nationaliteter står bakom olika grupperingar. En undersökning av organiserad narkotikabrottslighet i Sverige visade emellertid att personerna kom från flera länder och att det nordiska inslaget var betydande (Brå 2005:11). Ofta används också begreppet maffia för olika grupperingar, som rysk, jugoslavisk eller baltisk maffia. Dessa grupperingar liknar nästan aldrig det sicilianska originalet. Finckenauer och Warings bok "Russian Mafia in Amerika" är ett bra exempel. Forskarna fann inte några maffiagrupper utan lösa nätverk. Gärningspersonerna var knappast heller ryssar utan snarare georgier eller kom från andra länder. Förmodligen hade boken sålt sämre med titeln "Lösa georgiska nätverk i Amerika". På hemmaplan finns exemplet med bestsellern "Svensk maffia" (Wierup och Larsson 2007). En inte helt rättvisande titel på den svenska situationen.

På senare tid har uppmärksamheten riktats mot mobila vinningskriminella. Grupper från olika länder, bland annat Polen, Litauen och Rumänien, reser omkring och ägnar sig åt ficktjuveri och villainbrott.

\section{Infiltration av näringslivet}

Ibland förs fram att organiserad brottslighet infiltrerar näringslivet. Vad som egentligen menas är ganska oklart, men referenser kan göras till andra länder där 
kriminella kontrollerar delar av den offentliga upphandlingen. Genom korruption och andra former av otillåten påverkan gör stat och kommun affärer med företag kontrollerade av maffian (Arlacchi 1986). Resultat är att kontrakten blir dyra för skattebetalarna och i sämsta fall står hyreslängor och motorvägsbyggen halvfärdiga (Saviano 2008).

Nyss nämndes att kriminella engageras för indrivning av skulder, är involverade $i$ att tillgodose marknaden med svart arbetskraft och är verksamma inom häleribrottsligheten. Det är exempel på samarbetsformer mellan organiserad brottslighet och den legala ekonomin. Även om gråzonerna ibland gör det svårt att dra gränsen mellan illegal och legal ekonomi. Att tala om infiltration av näringslivet är därför knappast relevant. Till detta kommer att "acceptabla" varor som alkohol och cigaretter ofta finner vägen till köpmän med rymligt samvete.

Kriminella pengar söker sig också in i näringslivet. Särskilt i branscher som uppfattas som begripliga och någorlunda hemtama (Brå 2007:7). Det gäller restaurang, bygg, bilhandel och åkeri.

Undersökningar av den svenska narkotikabrottsligheten tyder dock på att det inte handlar så mycket om infiltration utan snarare att kriminella söker sig en bättre och säkrare framtid som egen företagare i den legala ekonomin (Brå 2007:7). Kriminell verksamhet går sällan som på räls utan är mycket stressfylld och ekonomiskt osäker (Brå 2007:4). Kurirer blir gripna, partier tas i beslag, leveranser försenas, kreditorer betalar inte, pengar försvinner på vägen och polisen är för närgången. För att reda ut olika problem kan inte kontakter tas hur som helst och säkerhetsarrangemangen hämmar effektiviteten. Inte heller här går det att tala om infiltration.

Det finns inga tecken på att kriminella kontrollerar ens delar av den offentliga upphandlingen (Brå 2010:9). Säkert finns en hel del oegentligheter och korruption från företags sida för att göra lönsamma affärer med den offentliga sektorn (Brå 2007:21). Men snarare gäller det oseriösa företag och personer inom företag. Dessa kan givetvis vara involverade i organiserad brottslighet och exempelvis pressa priserna genom omfattande svartarbete, men det är inte samma sak som att kontrollera offentlig upphandling. Vanlig "ekonomisk brottslighet" och en ekobrottslighet som ibland tagit sig organiserade former är en rättvisare stämpel än infiltration av organiserad brottslighet.

\section{Organiserad brottslighet, "the Nordic way"}

Läsaren av internationell litteratur om organiserad brottslighet har säkert svårt att känna igen sig i beskrivningen ovan. En förklaring är att det finns skillnader mellan olika regioner i världen. Som framgått utgörs denna brottslighet i Norden av en mer stillsam och "icke maffialik" typ utan gudfäder och skottsäkra limousiner. Per 
Ole Johansen (2007) skildrar "the Norwegian way" av organiserad brottslighet. Tage Alalehto (2011) ställer frågan varför Sverige inte är som Italien. Vi själva har skrivit om "the Nordic way" (2011).

Till detta kommer att organiserad brottslighet ofta skildras med övertoner och att organisationsgraden överdrivs (se mer i påföljande artikel av Larsson och Korsell). Nils Christie kritiserade Donald Cressey's "Theft of the nation" from 1969 (Nsfk report 1970). Christie ifrågasatte bilden av en tät och hierarkisk organisation och de (polis-) källor Christie byggde sin beskrivning av amerikank mafia på. Kritiken mot Cressey's beskrivning av en "nationwide alliance" av åtminstone "twenty-four tightly knit families" kritiseras fortfarande. ${ }^{1}$

Vad är förklaringen till att organiserad brottslighet i Norden ser ut som den gör?

Med undantag av Finland och den tyska ockupationen av Norge och Danmark har de nordiska länderna en lång tradition av fred och frihet. Skillnaden är därför stor mot exempelvis den sicilianska situationen med motstånd mot utländska erövrare, som avlöst varandra, och dagens situation med politisk korruption och en djup misstro mot politiska församlingar och myndigheter (Alalehto 2009). Krig, inbördeskrig och revolutioner skapar också laglösa tillstånd där möjligheter uppstår att exploatera marknader och överföra förmögenheter, något som gynnar organiserad brottslighet.

I alla nordiska länder har staten en särskild ställning. Staten betraktas i allmänhet som en representant för allmänheten. Staten tillhandahåller utbildning, hälsooch sjukvård, inkomsttrygghet genom olika socialförsäkringssystem och säkerhet. Flera länder har eller har haft långa socialdemokratiska regeringsinnehav med en tydlig allmän välfärdsinriktning. Det har säkert bidragit till synen på staten.

Visserligen förekommer nyliberala vindar med privatiseringar i släptåg, men styrkan i dessa har varit mindre än på andra håll i världen. I någon mån ligger välfärdsmodellen tämligen stadigt även för liberala och i någon mån konservativa partier. På arbetsmarknaden är det sällsynt med strejker och de stora arbetsgivarorganisationerna och fackföreningarna tenderar att komma överens.

Förtroendet är stort för myndigheterna, inte minst polisen och rättsväsendet i övrigt. Korruption uppfattas som något främmande, även om det inte är helt ovanligt att korruption förekommer mellan företag och upphandlande kommuner (Andersson 2002, Brå 2007:21, Brå 2010:9, Gedde-Dahl, Halstad och Magnussen 2008,). Överlag kännetecknas samhället av att människor känner förtroende och tillit (Rothstein 2003). På det hela taget litar människor på varandra till skillnad mot samhällen där man i högre grad måste förlita sig på närstående och där ära och hämnd är centrala inslag (Lappalainen 1993). Härigenom utgår de flesta från att myndigheterna är effektiva och upprätthåller allas likhet inför lagen. Utrymmet 
begränsas då för korruption, svågerpolitik och alternativa former av rättskipning.

De nordiska samhällena har en ganska lång demokratisk tradition, låt vara att Finlands historia är mer dramatisk. De lokala kommunerna och deras föregångare har en hög grad av självständighet, vilket innebär att de demokratiska församlingarna längre varit en angelägenhet för många människor. Demokrati på lokal nivå leder till ansvarstagande och långsiktighet där kollektiva intressen uppmuntrats. Härigenom har lokalsamhällena hyggligt kunna förebygga att miljöer uppstår där organiserad brottslighet kan verka utan insyn.

Även om Norge och Finland har en lång historia av relativ fattigdom, har levnadsstandarden ökat kraftigt i de nordiska länderna under efterkrigstiden. Välståndet är förhållandevis jämnt fördelat i jämförelse med många andra länder. En förklaring är jämlikhetstanken och socialdemokratins starka ställning. Den sociala rörligheten är jämförelsevis hög och studiefinansieringssystemen gör det möjligt för breda grupper att studera vid universitet och högskolor.

Följden är att färre människor sökt sig till kriminella karriärer som ett alternativ och en kompensation. På senare år har det dock blivit tydligare att det finns problem med ungdomsarbetslöshet, integration av människor från andra länder och en ökad segregation mellan socialgrupper. Det finns därför en del som talar för att utvecklingen går i fel riktning.

De nordiska länderna anses ha kommit långt när det gäller jämställdhet mellan män och kvinnor. Prostitution och koppleri är därför mindre vanligt än på andra hall. Sedan år 1999 är det i Sverige förbjudet att köpa sexuella tjänster. Norge har nyligen infört liknande bestämmelser och i Finland är det förbjudet att köpa sex från personer utsatta för människohandel.

Stora delar av de nordiska länderna består av landsbygd och mindre samhällen. Det finns få riktigt stora städer med en europeisk måttstock. Förutsättningarna minskar därför att driva storskalig organiserad brottslighet genom exempel hembränningsfabriker (Johansen 1996 och 2004). Det har lett till en småskalig organiserad brottslighet. Hur samhället är organiserat påverkar även hur brottsligheten är organiserad (Paoli 2003). I länder där familjen ofta är basen för legal näringsverksamhet tenderar också den organiserade brottsligheten att vara familjebaserad. I starkt hierarkiska samhällen med stora sociala skillnader följer den organiserade brottsligheten samma mönster. Det är därför inte särskilt förvånande att de nordiska länderna har en organiserad brottslighet som bygger på vänskap och kontakter. Helt enkelt ett större inslag av platta informella organisationer, för att låna en beskrivning från den legala ekonomin.

Av genomgången framgår att flera av de historiska omständigheter som förklarar uppkomsten av maffialiknande organisationer knappast har varit framträdande i Norden (Ianni and Reuss-Ianni1972, Paoli 2005). Staten är stark och oho- 
tad. Frågan är varför organiserad brottslighet finns trots uppräkningen av positiva faktorer. För det första är det marknadens osynliga hand (Korsell et al. 2010, Korsell, Skinnari \& Vesterhav 2009). Det kommer alltid att finnas en efterfrågan på illegala, billiga och "skattefria" varor och tjänster. Samtidigt kommer alltid kriminella entreprenörer att försöka tillgodose marknadens behov för att tjäna pengar. Arbetsdelning, kriminella affärsstrategier och säkerhetstänkande leder till organisatoriska lösningar för att få hjulen att rulla. För det andra kommer det alltid att finnas människor som känner sig uteslutna från samhället och frestelsen är därför stor att söka sig till grupper för att få bekräftelse och bli någon (Larsson 2008). I dag finns en trend när människor går in i gäng där broderskap och social gemenskap är centralt. Utvecklingen av gäng under de senaste tioårsperioderna kan kanske förklaras av att de nordiska länderna går mot ett mer delat samhälle med marginaliserade grupper, växande sociala problem, ekonomisk och social ojämnlikhet och förlorade livsmöjligheter (cf Björk 2006).

När det kommer till kritan kanske det är orättvist att lyfta fram Norden som ett specialfall för organiserad brottslighet. Vårt intryck är att forskning mer och mer lutar åt att småskalighet och ad hoc-grupperingar gäller mer generellt än vad man i förstone tror.

\section{Litteratur}

Aas, K. F (2007): Globalization and crime, key approaches to criminology. London: SAGE publications.

Alalehto, T. (2011). "Maffia: Är verkligen Sverige som Italien?” Under publicering.

Andersson, S. (2002). Corruption in Sweden. Exploring Danger Zones and Change. Umeå: Umeå universitet, statsvetenskapliga institutionen.

Arlacchi, P. (1986). Mafia Business. The mafia ethic \& the spirit of capitalism. London: Verso, 1986.

Brå 1999:6. MC-brott. Stockholm:Brottsförebyggande rådet.

Brå 2005:11. Narkotikabrottslighetens organisationsmönster. Stockholm: Brottsförebyggande rådet.

Brå 2006:6. Häleri: Den organiserade brottslighetens möte med den legala marknaden. Stockholm: Brottsförebyggande rådet.

Brå 2007:4. Vart tog alla pengarna vägen? En studie om narkotikabrottslighetens ekonomihantering. Stockholm: Brottsförebyggande rådet.

Brå 2007:7. Narkotikadistributörer. En studie av grossisterna. Stockholm: Brottsförebyggande rådet. 
Brå 2007:21. Korruptionens struktur i Sverige."Den korrupte upphandlaren" och andra fall om mutor, bestickning och maktmissbruk. Brottsförebyggande rådet. Stockholm.

Brå 2007:27. Organiserat svartarbete $i$ byggbranschen. Stockholm: Brottsförebyggande rådet.

Brå 2008:8. Otillåten påverkan mot brottsoffer och vittnen. Om ungdomsbrott, relationsvåld och organiserad brottslighet. Stockholm: Brottsförebyggande rådet.

Brå 2008:24. Sexuell människohandel. En fråga om tillgång och efterfrågan. Stockholm: Brottsförebyggande rådet.

Brå 2009:7. Polisens möte med organiserad brottslighet. En undersökning om otillåten påverkan. Stockholm: Brottsförebyggande rådet.

Brå (2010). Lokal organiserad brottslighet. En handbok om motåtgärder. Stockholm: Brottsförebyggande rådet.

Brå 2010:9. Karteller och korruption. Otillåten påverkan mot offentlig upphandling. Stockholm: Brottsförebyggande rådet.

Christie, N. (1970). "Om organiserad brottslighet." Rapport fra Det Nordiska forskarseminariet. Nordisk samarbeidsråd for kriminologi. Stockholm.

Fickenauer, J. O. och Waring, E. J. (1998). Russian mafia in America. Immigration, culture and crime. Boston: Northeastern University Press.

Gedde-Dahl, S. Halstad, A. och Magnussen, A.E. (2008). Korrupsjon i Norge. Oslo: Kagge.

Johansen, P.O. (1993). Markedet som ikke ville dø. Forbudstiden og de illegale alkoholmarkedene $i$ Norge og USA. Oslo: Rusmiddeldirektoratet.

Johansen, P.O. (1996). Nettverk i gråsonen. Et perspektiv på organisert kriminalitet. Ad Notam, Gyldendal. Oslo.

Johansen, P. O. (2004). Den illegal sprite. Fra forbudstid til polstreik. Oslo: Unipub.

Johansen, P. O. (2005). "Organised crime, Norwegian style". I: van Duyne m. fl. The Organised crime economy. Managing crime markets in Europe. Nijmegen: Wolf Legal Publishers.

Johansen, P. O. (2009). "Organised crime Norwegian style ... used to be". In: Ingvaldsen, K. \& Lundgren Sørli, V. (ed.). Organised Crime. Norms, markets, regulation and research. Oslo: Unipub.

Junninen, M. (2006). Adventurers and risk-takers: Finnish professional criminals and their organisations in the 1990s cross-border criminality. Helsingfors: European Instititue for crime prevention and control, affiliated with the United Nations (Heuni).

Junninen, M. \& Aromaa, K. (1999). Eastern Crime. Helsingfors: European In- 
stititue for crime prevention and control, affiliated with the United Nations (Heuni).

Korsell, L. (2008). "Hur organiserad är den organiserade brottsligheten?" I: Alalehto, T. och Larsson, D. (red.). Den ljusskygga ekonomin. Organiserad och ekonomisk brottslighet. Umeå: Umeå universitet.

Korsell, L., Skinnari, J. och Vesterhav, D. (2009). Organiserad brottslighet $i$ Sverige. Malmö: Liber.

Korsell, L. och Skinnari, J. (2010). "Situational prevention against unlawful influence from organised crime". I: Bullock, K.; Clarke, R. och Tilley, N. Situational prevention of organised crimes. Devon: Willan Publishing.

von Lampe, K. (2005). "Explaining the emergence of the cigarette black market in Germany". I: van Duyne m. fl. The Organised crime economy. Managing crime markets in Europe. Nijmegen: Wolf Legal Publishers.

von Lampe, K. (2009). Definitions of organized crime. www.organized-crime.de Lappalainen, T. (1993). Maffia. Stockholm: Bokförlaget T. Fisher \& Co.

Larsson, P. (2008). Organisert Kriminalitet. Oslo: Pax.

Larsson, P. (2009): "Up in smoke! Hash-smuggling the Norwegian way." I: Ingvaldsen, K. och Lundgren Sørli, V. (red.). Organised Crime. Norms, markets, regulation and research. Oslo: Unipub.

Larsson, P. (2009b). Det norske cannabismarkedet. Report to Sirus, Oslo.

Lehti, M. och Aromaa, K. (2004). "Trafficking in Women and Children". I: Nevala, S. \& Aromaa, K. Organised crime, trafficking, drugs: Selected papers at the Annual Conference of the European Society of Criminology, Helsinki 2003. Report 42. Helsinki: European Institute for Crime Prevention and Control affiliated with the United Nations (Heuni).

Levi, M. (2002). "Perspectives on 'Organised Crime': An Overview." The Howard Journal vol 37, no 4.

Paoli, L. (2003): Mafia Brotherhoods. Organized Crime Italian Style. Oxford University press.

Rothstein, B. (2003). Sociala fällor och tillitens problem. Stockholm: SNS.

Sandberg, S. och Pedersen, W. (2009): Street Capital. Black cannabis dealers in a white welfare state. Policy Press, Bristol.

Saviano, R. (2008). Gomorra. En resa i Camorrans land. Stockholm: Brombergs.

Viuhko, M. och Jokinen, A. (2009). Human trafficking and organised crime. Trafficking for sexual exploitation and organised procuring in Finland. Report 62. Helsinki: The European Institute for Crime Prevention and Control, affiliated with the United Nations (HEUNI).

Viuhko, M. et al. (2009). Corruption on the Finnish-Russian Border. Experiences 
and observations of Finnish and Russian civil servants and businesspersons on corruption on the border between Finland and Russia. Report 61. Helsinki: The European Institute for Crime Prevention and Control, affiliated with the United Nations (HEUNI).

Wierup, L. och Larsson, M. (2007). Svensk maffia. En kartläggning av de kriminella gängen. Stockholm: Norstedts.

Wierup, L. och de la Reguera, E. (2010). Kokain. Drogen som fick medelklassen att börja knarka och länder att falla samman. Stockholm: Norstedts.

\section{Notes:}

1 Se antologin Understanding Organized Crime in Global Perspective. Ed: Ryan, P. J. och Rush, G. E.

Adress:

Lars Korsell

Brottsförebyggande rådet

Box 1386

SE-111 93 Stockholm

Paul Larsson

Politihøgskolen

Slemdalsveien 5

NO 0301 Oslo 